\title{
PENGARUH GAYA KEPEMIMPINAN TRANSFORMASIONAL DAN BUDAYA ORGANISASI TERHADAP PRODUKTIVITAS KERJA KARYAWAN PT BANK MANDIRI TBK UNIT RRCR 2 JAKARTA PUSAT
}

\author{
1*Priehadi Dhasa Eka, ${ }^{2}$ Dominicus Angga Wibowo \\ Universitas Pamulang, Tangerang Selatan, Banten, Indonesia \\ *dosen01577@unpam.ac.id
}

\begin{abstract}
Abstrak
Penelitian ini bertujuan untuk membuktikan apakah ada pengaruh Gaya Kepemimpinan Transformasional dan Budaya Organisasi terhadap Produktivitas Kerja Karyawan PT Bank Mandiri Tbk Unit RRCR 2 Jakarta Pusat. Penelitian ini menggunakan metode kuantitatif. Analisis data menggunakan uji validitas, uji reliabilitas, uji asumsi klasik, analisis regresi, analisis koefisien korelasi, analisis koefisien determinasi dan uji hipotesis. Hasil penelitian ini adalah, Gaya Kepemimpinan Transformasional dan Budaya Organisasi berpengaruh signifikan terhadap Produktivitas Kerja dengan persamaan regresi $Y=12,150+0,809 X_{1}+0,655 X_{2}$. Nilai korelasi sebesar 0,711 artinya variabel bebas dengan variabel terikat memiliki tingkat hubungan yang kuat. Nilai koefisien determinasi sebesar $59,5 \%$ sedangkan sisanya sebesar $40,5 \%$ dipengaruhi oleh factor lain. Terdapat pengaruh signifikan secara simultan dengan Uji hipotesis diperoleh nilai $F_{\text {hitung }}>F_{\text {tabel }}(100,251>3,06)$, dengan demikian maka $\mathrm{H}_{0}$ ditolak $\mathrm{H}_{3}$ diterima.
\end{abstract}

Kata Kunci: Gaya Kepemimpinan Transformasional, Budaya Organisasi, Produktivitas Kerja

\section{Abstract}

This research aims to prove whether there is an influence of Transformational Leadership Style and Organizational Culture on Employee Productivity of PT Bank Mandiri Tbk Unit RRCR 2 Central Jakarta. This research uses quantitative methods. Data analysis uses validity tests, reliability tests, classical assumption tests, regression analysis, correlation coefficient analysis, determination coefficient analysis and hypothesis tests. The results of this study are, Transformational Leadership Style and Organizational Culture significantly affect Work Productivity with regression equation $Y=12,150+0.809 X 1+0.655 X 2$. A correlation value of 0.711 means that a free variable with a bound variable has a strong relationship rate. The coefficient of determination is $59.5 \%$ while the remaining $40.5 \%$ is influenced by other factors. There is a significant influence simultaneously with the hypothesis test obtained the value of Fhitung > Ftabel $(100,251>3.06)$, thus HO is rejected $\mathrm{H} 3$ accepted.

Keywords: Transformational Leadership Style, Organizational Culture, Work Productivity

\section{PENDAHULUAN}

Sumber daya manusia merupakan aset terpenting dalam sebuah organisasi bisnis atau sebuah perusahaan, karena perannya sebagai subjek pelaksana kebijakan dan kegiatan operasional perusahaan. Adanya sumber daya manusia yang memiliki kinerja yang baik mampu memberikan hasil yang sangat optimal bagi perusahaan. Agar mendapatkan hasil kinerja yang baik dan optimal, sumber daya manusia harus dikelola dengan sangat baik sehingga sumber daya manusia dalam suatu organisasi atau perusahaan merasa nyaman dalam menjalankan segala aktivitas dan tugasnya serta mampu mendapatkan hasil yang maksimal. Sumber daya manusia merupakan kemampuan terpadu dari daya pikir dan daya fisik yang dimiliki individu. Kemampuan sumber daya manusia tidak dapat dilihat dari satu sisi saja, namun harus mencakup keseluruhan dari daya pikir dan juga fisiknya.

Karyawan merupakan sumber daya manusia yang penting dalam sebuah organisasi atau perusahaan yang bertindak sebagai perencana, pelaksana, dan 
pengendali yang selalu berperan aktif dalam mewujudkan suatu tujuan organisasi. Karyawan dalam hal ini sebagai penunjang tercapainya tujuan organisasi yang memiliki pikiran, perasaan dan keinginan tentunya mempengaruhi sikap terhadap pekerjaan yang dilimpahkan atau dibebankan. Sikap karyawan terhadap pekerjaan tersebut dikenal dengan istilah kepuasan kerja yang ditimbulkan oleh pekerjaan, peralatan, lingkungan dan kebutuhan.

Peranan karyawan terhadap pekerjaan yang strategis dalam mencapai tujuan pembangunan nasional mengakibatkan perlu adanya penggunaan dan pengawasan yang efektif, sehat, wajar, dan mampu melindungi secara baik dana masyarakat yang dititipkan kepadanya, serta mampu menyalurkan dana masyarakat tersebut dibidang yang produktif bagi pencapaian sasaran pembangunan.

Bank Mandiri merupakan salah satu bank terbesar yang beroperasi di Indonesia. Selain telah memiliki banyak nasabah dan memiliki kantor cabang di seluruh Indonesia, Bank Mandiri juga telah meraih banyak prestasi di dunia perbankan. Bank Mandiri juga memiliki staf ahli tetap dan tidak tetap yang mempunyai pengalaman profesioal dibidangnya masing - masing selama bertahun - tahun, terlebih staff ahli dalam unit RRCR Jakarta 2 Thamrin yang fokus pada masalah kredit macet nasabah.

Dalam penelitian kali ini, peneliti memfokuskan penelitian pada Unit RRCR (Regional Retail Collection \& Recovery) Jakarta 2 Jakarta Pusat. Dimana dalam unit terbagi menjadi 3 (tiga) bagian unit kerja collection (penagihan) yaitu, Mortgage, Personal Loan atau Kredit Tanpa Agunan (KTA), dan Credit Card. Unit kerja ini memiliki fungsi sebagai bagian penting dari perusahaan, dimana masing - masing unit ini memiliki tugas untuk mengelola piutang atau account receivable sebagai akibat adanya perjanjian pembiayaan. Maka dari itu segala bentuk bentuk piutang dari pihak debitur harus dikelola dengan baik oleh staff penagiham atau collection.
Berikut adalah penjelasan secara singkat pengertian dari Unit Kerja RRCR Jakarta 2 Jakarta Pusat. Mortgage Collection adalah bagian penagihan instrument utang berupa kredit berjangka panjang yang dilakukan dengan memberikan hak tanggungan property dari peminjam kepada pemberi pinjaman sebagai jaminan terhadap kewajibannya. Personal Loan Collection adalah bagian penagihan sebuah kredit atau pinjaman uang online yang dikhususkan untuk perorangan, yang dalam proses peminjamannya tanpa memerlukan agunan atau jaminan seperti sistem yang diberlakukan pada peminjaman selain KTA lainnya. Credit Card Collection adalah bagian penagihan suatu jenis penyelesaian transaksiritel dan sistem kredit dengan menggunakan kartu yang diterbitkan oleh Bank Mandiri.

Salah satu gaya kepemimpinan yang dianggap mampu meningkatkan produktivitas adalah gaya kepemimpinan transformasional. Gaya kepemimpinan transformasional ini dianggap mampu memberikan stimulus terbentuknya produktivitas dalam suatu organisasi atau perusahaan.

Kepemimpinan transformasional digambarkan sebagai gaya kepemimpinan yang dapat membangkitkan atau memotivasi karyawan sehingga dapat berkembang dan meningkatkan produktivitas kerja karyawan.

Berdasarkan tabel diatas menunjukkan bahwa pada penilaian kepemimpinan masih didapati beberapa hasil skor yang belum menunjukkan persentase yang baik. Dimana hasil persentase yang paling rendah ada para kriteria komunikasi dengan skor sebesar $56 \%$ Ini menunjukkan bahwa kepemimpinan pada PT Bank Mandiri Unit RRCR 2 Jakarta Pusat masih belum menunjukkan hasil yang baik.

Fenomena lain yang terjadi pada penilitian ini didasarkan pada aspek budaya organisasi yang terjadi di perusahaan ini dan itu sangat berpengaruh terhadap produktivitas dari karyawan yang ada pada perusahaan tersebut. Selain itu, 
dibutuhkan budaya organisasi yang baik untuk menciptakan produktivitas dalam diri karyawan sehingga meningkatkan kinerja organisasi. Selain itu budaya organisasi yang baik akan sangat dibutuhkan untuk membentuk dan meningkatkan kinerja serta produktivitas kerja karyawan. Banyak organisasi saat ini merasa perlu mengubah budaya organisasi atau perusahaan guna menjamin kelangsungan hidup suatu organisasi dan untuk memperoleh keunggulan kompetitif. Budaya organisasi merupakan filosofi dasar organisasi yang memuat

keyakinan, norma - norma dan nilai bersama yang menjadi karakteristik inti tentang bagaimana cara melakukan sesuatu dalam organisasi.

Berdasarkan pada penilaian karakteristik pegawai PT Bank Mandiri Tbk unit RRCR 2 Jakarta Pusat dapat dilihat bahwa selama periode 2016 hingga 2020 masih belum didapati semua penilaian memenuhi nilai persentase yang maksimal. Dimana pada kriteria penilaian karakteristik pegawai pada indikator kehadiran masih menjadi perhatian dimana persentase paling rendah $75 \%$ pada tahun 2016 dan 2020. Selain itu juga pada indikator perilaku pada tahun 2017 memilikipersentase paling rendah sebesar 68\% dan meningkat di tahun 2018 sebesar $86 \%$ dan pada tahun 2019 sebesar $98 \%$ akan tetapi kembali menurun di tahun 2020 dengan nilai persentase sebesar $76 \%$.

Produktivitas kerja yang optimal merupakan gambaran dari sumber daya manusia yang berkualitas. Produktivitas merupakan kemampuan setiap orang, sistem atau suatu perusahaan dalam menghasilkan sesuatu yang diinginkan dengan cara memanfaatkan sumber daya secara efektif dan juga efisien.

Berdasarkan pengamatan awal dan wawancara yang dilakukan peneliti diperoleh informasi bawa terdapat penurunan angka produktivitas kerja karyawan PT Bank Mandiri Tbk Unit RRCR 2 Jakarta Pusat. Penurunan ini ditunjukkan dengan menurunnya angka pencapaian target penagihan ataupun target proses penagihan melalui sambungan telepon kepada debitur atau melakukan penagihan langsung ke rumah debitur.

Berikut ini adalah data penilaian produktivitas selama lima tahun terakhirdi PT. Bank Mandiri Unit RRCR 2 Jakarta Pusat dari proses kerja yang dilakukan berdasarkan standar operasional perusahaan yang diberikan dan ditargetkan.

Berdasarkan tabel diatas, dapat dilihat bahwa target pencapaian dari outstanding call dan visit debitur PT. Bank Mandiri Unit RRCR Jakarta 2 belum mampu semua dicapai sesuai dengan targetnya dimana pada 2 tahun terakhir di tahun 2019 memiliki jumlah target pencapaian target kerja yang baik sebesar

60.325 calls dari target 60.000 calls dan 6.145 visit dari target 6.240. Pada tahun 2020 mengalami penurunan jumlah target kerja sebesar 61.234 calls dari target

61.700 calls dan 6.265 visit dari target 6.660 visit. Tentu hal ini menjadi perhatian khusus bagi perusahaan dengan penurunan yang cukup signifikan terhadap produktivitas kerja karyawan dalam pencapaian target yang telah ditetapkan oleh perusahaan. Ini menjadikan perusahaan tetap harus terus memperbaiki produktivitasnya. Kondisi seperti ini mengindikasikan bahwa produktivitas kerja karyawan bisa dikatakan belum cukup baik.

Selain itu berdasarkan pengamatan awal dan wawancara yang dilakukan peneliti, diperoleh informasi bahwa produktivitas karyawan PT. Bank Mandiri Unit RRCR Jakarta 2 Thamrin sedang mengalami penurunan pada tahun 2019. Penurunan ini ditunjukkan oleh kehadiran karyawan yang terlambat masuk kerja antara 10-30 menit. Manajer dianggap kurang tegas dalam memberikan sanksi terhadap karyawan yang sering terlambat masuk kerja. Selain itu, ada beberapa karyawan yang sering tidak masuk dan sangat menggangu produktivitas krja pada perusahaan.

Selain itu juga terdapat beberapa karyawan yang harus resign sebelum 
kontrak kerja mereka berakhir. Mereka beralasan bosan terhadap aktivitas kerja dan tekanan yang sangat menuntut hasil kerja yang lebih. Hal ini menyebabkan pihak manajer kesulitan untuk melakukan perekrutan karyawan dalam waktu yang singka karena karyawan baru hanya memiliki waktu sebentar untuk melaksanakan training sehingga kemungkinan penyebab kinerja kerja yang kurang maksimal dapat terjadi. Berikut ini adalah data absensi karyawan PT. Bank Mandiri Unit RRCR Jakarta 2 Thamrin pada tahun 2019.

Jika dilihat pada tabel diatas, jumlah datang terlambat yang dilakukan oleh karyawan masih banyak dilakukan, dimana pada bulan januari tahun 2020 memiliki jumlah keterlambatan paling banyak di tahun 2020 sebanyak 10 kali jumlah keterlambatan dari karyawan. Tentu saja hal ini sangat berpengaruh terhadap kedisiplinan dan juga produktivitas yang dihasilkan dari para karyawan.

Berdasarkan latar belakang tersebut, maka dalam penelitian ini penulis perlu meneliti lebih lanjut mengenai "Pengaruh Gaya Kepemimpinan Transformasional dan Budaya Organisasi Terhadap Produktivitas Kerja Karyawan PT. Bank Mandiri Unit RRCR Jakarta 2 Jakarta Pusat".

\section{METODE}

Penelitian kuantitatif merupakan salah satu jenis penelitian yang spesifikasinya adalah sistematis, terencana, dan terstruktur dengan jelas sejak awl hingga pembuatan desain penelitiannya. Definisi lain menyebutkan penelitian kuantitatif adalah penelitian yang banyak menuntut penggunaan angka, mulai dari pengumpulan data, penafsiran terhadap data tersebut, serta penampilan dari hasilnya. Demikian pula pada tahap kesimpulan peneilitian akan lebih baik bila disertai dengan gambar, table, grafik, atau tampilan lainnya. Menurut (Sugiyono, 2017:38) Variabel penelitian adalah segala sesuatu yang berbentuk apa saja yang ditetapkan oleh peneliti untuk dipelajari sehingga diperoleh informasi tentang hal tersebut, kemudian ditarik kesimpulannya. Sesuai dengan judul penelitian yang dipilih penulis yaitu Pengaruh Gaya Kepemimpinan Transformasional Dan Budaya Organisasi Terhadap Produktivitas Kerja Karyawan. Penulis mengelompokan variabel yang digunakan dalam penelitian ini menjadi variabel independen $(X)$ dan variabel dependen (Y). Adapun penjelasannya sebagai berikut : Variabel independen (variabel bebas) dalam penelitian ini adalah keterampilan kerja dan lingkungan kerja. Sedangkan variabel dependen (variabel terikat) adalah prestasi kerja. Populasi yang digunakan dalam penelitian ini adalah seluruh karyawan PT. Bank Mandiri Tbk Unit RRCR Jakarta 2 Thamrin dengan jumlah 140 karyawan.

\section{HASIL PENELITIAN DAN PEMBAHASAN}

Berdasarkan hasil pengumpulan data baik primer maupun sekunder, diperoleh gambaran hasil penelitian. Data yang terkumpul kemudian diolah sesuaidengan jumlah responden yang telah ditetapkan sebelumnya, yaitu angket yang disebarkan kepada responden sebanyak 140 angket dan telah dikembalikan seluruhnya. Setelah seluruh angket terkumpul ternyata secara keseluruhn memenuhi syarat untuk dianalisis dan diinteprestasikan guna memecahkan permasalahan yang dirumuskan sebelumnya.

\section{Pembahasan Deskriptif}

Variabel yang digunakan dalam penelitian ini adalah GayaKepemimpinan Transformasional (X1), Budaya Organisasi (X2) dan Produktivitas Kerja (Y). Dalam menganalisis, penulis menggunakan analisis deskriptif dengan memberikan gambaran mengenai hasil penelitian, bagaimana karakteristik subyek penelitian sehubungan dengan variabel yang diteliti. Sebelum dilakukan analisis, terlebih dahulu dilakukan pembobotan terhadap skor masing - masing variabel dengan dalam melakukan analisis.

\section{Teknik Analisa Data}

Menurut Sugiyono (2017:89) “Analisa data adalah proses mencari dan menyusun 
data secara sistematis data yang diperoleh dari hasil wawancara, catatan lapangan dan dokumentasi, dengan cara mengorganisasikan data kedalam kategori, menjabarkan kedalam unit - unit, melakukan sintesa, meyusun kedalam pola, memilih mana yang penting dan yang akan dipelajari, dan membuat kesimpulan sehingga mudah dipahami oleh diri sendiri maupun orang lain. Miles and Huberman (Sugiyono, 2017:91) mengemukakan terdapat 3 langkah dalam analisis data, yaitu reduksi data, display data, dan verifikasi data. Berikut metode analisis data yang digunakan dalam melakukan penelitian ini adalah :

\section{KESIMPULAN DAN SARAN Kesimpulan}

Berdasarkan hasil penelitian serta analisis yang telah saya lakukan serta pembahasan mengenai "Pengaruh Gaya Kepemimpinan Transformasional Dan Budaya Organisasi Terhadap Produktivitas Kerja Pada Karyawan PT. Bank Mandiri Tbk Unit RRCR Jakarta 2 Thamrin", maka dapat disimpulkan sebagai berikut:

1. Gaya kepemimpinan transformasional berpengaruh signifikan terhadap produktivitas kerja karyawan dengan persamaan regresi $\mathrm{Y}=17,511+1,166 \mathrm{X}_{1}$ nilai koefisien korelasi sebesar 0,692 artinya kedua variabel mempunyai tingkat hubungan yang kuat. Nilai koefisien determinasi sebesar $47,6 \%$. Uji hipotesis diperoleh nilai $t_{\text {hitung }}>t_{\text {tabel }}$ $(10,162>1,978)$ dengan nilai signifikansi value < Sig 0,05 $(0,000<0,05)$. Dengan demikian Dengan demikian maka $\mathrm{H}_{0}$ ditolak dan $\mathrm{H}_{2}$ diterima. Hal ini menunjukkan bahwa terdapat pengaruh yang positif dan signifikan antara budaya organisasi terhadap produktivitas kerja karyawan PT. Bank Mandiri Tbk Unit RRCR Jakarta 2 Thamrin.

2. Budaya organisasi berpengaruh signifikan terhadap produktivitas kerja karyawan dengan persamaan regresi $Y=$ $20,363+1,072 X_{2}$, nilai koefisien korelasi sebesar 0,654 artinya kedua variabel mempunyai tingkat hubunan yang kuat. Nilai koefisien determinasi sebesar $42,8 \%$. Uji hipotesis diperoleh nilai $t_{\text {hitung }}>t_{\text {tabel }}(11,272>1,978)$ dengan nilai signifikansi

value $<$ Sig $0,05(0,000<0,05)$. Dengan demikian Dengan demikian maka $\mathrm{H}_{0}$ ditolak dan $\mathrm{H}_{1}$ diterima, artinya terdapat pengaruh yang positif dan signifikan antara gaya kepemimpinan transformasional terhadap produktivitas kerja karyawan PT. Bank Mandiri Tbk Unit RRCR Jakarta 2 Thamrin.

3. Gaya kepemimpinan transformasional dan budaya organisasi berpengaruh signifikan terhadap produktivitas kerja karyawan dengan persamaan regresi $Y=$ $12,150+0,809 X_{1}+0,655 X_{2}$, nilai koefisien korelasi sebesar 0,771 artinya kedua variabel mempunyai tingkat hubungan yang kuat. Nilai koefisien determinasi sebesar 59,4\%. Uji hipotesis diperoleh nilai $F_{\text {hitung }}>F_{\text {tabel }}(100,251>3,06)$, dengan nilai signifikansi value $<$ sig. $0,05(0,000<$ $0,05)$. Dengan demikian Dengan demikian maka $\mathrm{H}_{0}$ ditolak dan $\mathrm{H}_{3}$ diterima. Hal ini menunjukkan bahwa terdapat pengaruh yang positif dan signifikan secara simultan antara gaya kepemimpinan transformasional terhadap produktivitas kerja karyawan PT. Bank Mandiri Tbk Unit RRCR Jakarta 2 Thamrin.

\section{Saran}

1. Gaya Kepemimpinan Transformasional (X1)

Dari hasil penelitian variabel gaya kepemimpinan transformasional, pernyataan hasil kuesioner yang nilai paling rendah pada indikator "Inspirational Motivation" yaitu "Pimpinan saya belum mendorong karyawan lain agar melakukan pekerjaan terbaik berdasarkan kemampuan dan kapasitas yang dimiliki" dan pada indikator "Idealized Influence" yaitu "Pimpinan saya belum menjelaskan visi masa depan dengan baik". Disarankan agar pimpinan mampu memberikan dorongan serta 
motivasi yang lebih kepada karyawan serta memberikan penjelasan yang baik tentang misi perusahaan kepada karyawan.

\section{Budaya Organisasi (X2)}

Dari hasil penelitian variabel budaya organisasi, pernyataan hasil kuesioner yang nilai paling rendah pada indikator "Penampila Karyawan" yaitu "Penampilan yang rapi dinilai belum lebih baik dalam melakukan setiap pekerjaan" dan pada indikator "Kerja Sama" yaitu "Karyawan belum mendapatkan bantuan dari orang lain ketika menghadapi masalah". Disarankan agar perusahaan lebih memperhatikan kembali penampilan karyawannya serta memberikan dorongan kepada karyawan untuk saling membantu agar terjalinnya kerja sama yang baik diantara karyawan.

\section{Produktivitas Kerja}

Dari hasil penelitian variabel produktivitas kerja, pernyataan hasil kuesioner yang nilai paling rendah pada indikator "Kemampuan" yaitu "Saya belum berusaha memberikan yang terbaik bagi perusahaan" dan pada indikator "Meningkatkan hasil yang dicapai" yaitu "Saya belum membimbing rekan kerja saya menjadi lebih baik". Disarankan agar perusahaan lebih memperhatikan karyawan dalam segi kemampuan agar karyawan mampu memberikan hal yang terbaik bagi perusahaan serta nendorong karyawan agar selalu bisa memberikan motivasi dan bantuan terhadap karyawan yang lain sehingga produktivitas kerja dapat dihasilkandengan baik.

\section{DAFTAR PUSTAKA}

Affandi, A., et al.. (2020). Optimization of MSMEs Empowerment in Facing Competition in the Global Market during the COVID-19 Pandemic Time. Systematic Reviews in Pharmacy, 11(11), 1506-1515.

Andriani, J \& Purnomo, S. (2019). Pengaruh Budaya Organisasi Dan Disiplin Kerja Terhadap Produktivitas Kerja
Karyawan Pada Koperasi Simpan Pinjam Sejahtera Bersama Bogor, Jurnal Ilmiah Feasible Universitas Pamulang. 1(2).

Bagian Penerbitan Sekolah Tinggi Ilmu Ekonomi YKPN. Sudjana. (2015). Metoda Statistika. Edisi 6. Bandung. Tarsito

Ghozali, Imam. (2013). Aplikasi Analisis dengan Program SPSS. Semarang: Undip.

Handoko. (2014). Kiat-kiat Melejitkan Karir Bagi Karyawan Profesional, Bandung: Kaifa Press,

Hasibuan, Malayu S.P. (2011). Manajemen Sumber Daya Manusia, Reformasi Birokrasi Dan Manajemen Pegawai Negeri Sipil (cetakan kelima). Bandung : PT RefikaAditama.

Hermawati, R., et al. (2020). The Effect of Trilogy Leadership Style and Organization Culture on School Performance: Evidence form Indonesian Senior High School. PalArch's Journal of Archaeology of Egypt/Egyptology, 17(6), 8512-8537.Fdisiplin

Insani, P. B. E. B. (2020). Hubungan Gaya Kepemimpinan Dengan Produktivitas Kerja Pegawai Bmt El Bina Insani Cugenang. Jurnal Agrita Vol, 2(1).

Ipmawan, H, (2016), Pengaruh Kepemimpinan Transformasional, Motivasi Kerja Dan Kompetensi Terhadap Kinerja (Studi Kasus Departement Technical PT. Surya Toto Indonesia Tbk Divisi Fitting Tangerang Selatan), Jurnal Ekonomi Universitas Indraprasta. 2(1).

Mangkunegara, A.A. Anwar Prabu. (2006). Perencanaan dan Pengembangan Manajemen Sumber Daya Manusia. Bandung: PT. Refika Aditama.

Manullang. (2013). Manajemen. Yogyakarta : Penerbit Gadjah Mada University Press

Marpaung, Marudut. (2014). Pengaruh Gaya Kepemimpinan Dan Team Work Terhadap Intensi Keluar Di Koperasi Mandiri Sejahtera Tangerang Banten. Jurnal Ilmiah Manajemen SDM Universitas Pamulang. 2(1). 
Muslimat, A., et al.. (2020). Effect Of Organizational Commitment On The Sustainability Performance Of Indonesian Industries. PalArch's Journal of Archaeology of Egypt/Egyptology, 17(6), 8330-8347.

Nurjaya, N., et al. (2021). Pengaruh Kompetensi Sumber Daya Manusia Dan Kemampuan Pemanfaatan Teknologi Terhadap Kinerja Aparatur Desa Pada Kantor Kepala Desa Di Kabupaten Gunungkidul, Yogyakarta. JENIUS (Jurnal Ilmiah Manajemen Sumber Daya Manusia), 4(3), 332-346.

Pawar, A., et al. (2020). Organizational Servant Leadership. International Journal of Educational Administration, Management, and Leadership, 63-76.

Prayogo, Mulyadi., Wicaksono. (2019). Pengaruh Motivasi Dan Budaya OrganisasiTerhadap Kinerja Karyawan PT. Fenixindo Global Mandiri (Veneta System). Jurnal Ilmiah Manajemen SDM Universitas Pamulang. 3(1).

Rifiansyah, Ogi. (2016). Pengaruh Gaya Kepemimpinan Transformasional Dan Budaya Organisasi Terhadap Kinerja Karyawan Pada PT. Bank Rakyat Indonesia (Persero), Tbk Kantor Wilayah Pekanbaru. JOM Fisip. 3(2).

Santoso, Singgih, (2007). "Total Quality Management (TQM) dan Six Sigma", PT Elex Media Komputindo, Jakarta

Sedarmayanti. (2010). Sumber Daya manusia dan produktivitas. Jakarta: CV Mandar Maju. (2011), Sumber Daya Manusia dan Produktivitas Kerja, CV. Mandar Maju, Bandung. semarang. Semarang.

Setyo, D., Djudi, P., Gunawan, M \& Nurtjahjono, E. (2016). Pengaruh Gaya Kepemimpinan Transformasional Terhadap Kinerja Karyawan Melalui Kepuasan Kerja Karyawan Sebagai Variabel Mediasi. Jurnal Administrasi Bisnis (JAB). 39(1).

Siagian, Sondang P. (2015). Manajemen Sumber Daya Manusia. Ed. 1, Cet. 23.

Simamora, Henry. (2014). Manajemen Sumber Daya Manusia. Yogyakarta.
Sugiyono, (2016). Metode Penelitian Kuantitatif Kualitatif dan $R \quad \mathcal{E} D$. Bandung:Alfabetta.

Suharsimi Arikunto. (2012). Dasar-dasar evaluasi Pendidikan. Jakarta: Bumi Aksara

Sularmi, L., Apriyanti, N, H. (2019). Pengaruh Budaya Organisasi Dan Disiplin Terhadap Kinerja Kerja Karyawan Pada PT. Mega Perintis Tbk. Jurnal Ilmiah Manajemen SDM Universitas Pamulang. 3(1).

Sulastri, L., et al.. (2020). The Role of Decision Support System and Risk Management Using Social Media Promotion. International Journal of Psychosocial Rehabilitation, 24(1).

Sunarsi, D. (2017). Pengaruh Kepemimpinan Dan Budaya Organisasi terhadap Kinerja Karyawan Pada Cabang Pembantu Bank DKI Pondok Labu-Jakarta Selatan. JENIUS, 1(2), 21.

Sunyoto, Danang. (2012). Manajemen Sumber Daya Manusia. Cetakan Pertama.

Suryani, L. (2018) Pengaruh Gaya Kepemimpinan Transaksional Dan Gaya Kepemimpinan Transformasional Terhadap Kepuasan Kerja Karyawan Pada PT. Jasa Raharja. Jurnal Semarak Universitas Pamulang. 1(2).

Sutrisno, Edy. (2011). Budaya Organisasi. Cetakan Kedua. Jakarta : Penerbit Kencana

Syah, Muhibbin. (2013). Psikologi Pendidikan dengan Pendidikan Baru. Bandung

Wijayanto. (2012). Pengantar Manajemen. Jakarta : Penerbit PT Gramedia Pustaka Utama.

Yanuardi, R. (2013). Pengaruh Keterampilan Kerja dan Pengetahuan Administrasi terhadap Kinerja Pegawai Administrasi Fakultas Ekonomi Universitas Negeri Padang.

Suwanto, S., et al.. (2021). Pengaruh Motivasi Dan Pengalaman Kerja Terhadap Produktivitas Karyawan Pada Happy Restaurant Di Bandung. Jurnal Ekonomi Efektif, 3(4), 546-554. 